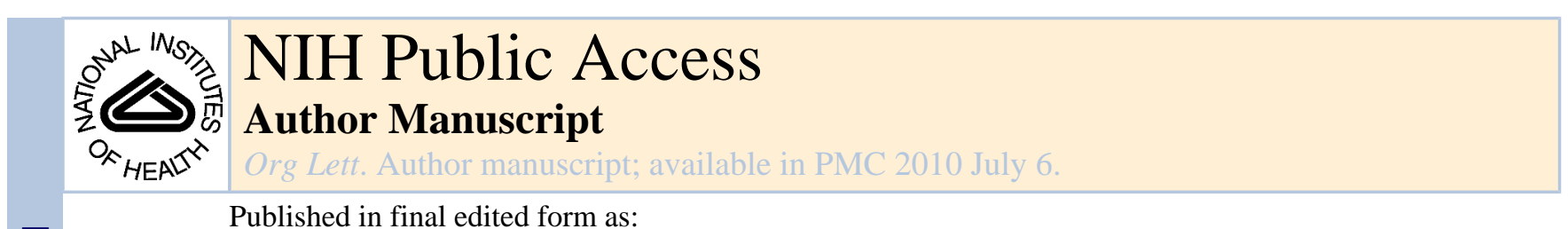

Org Lett. 2005 September 1; 7(18): 3905-3908. doi:10.1021/o1051307b.

\title{
Reactions of (Trialkylsilyl)vinylketenes with Lithium Ynolates: A New Benzannulation Strategy
}

\author{
Wesley F. Austin, Yongjun Zhang, and Rick L. Danheiser ${ }^{\star}$ \\ Department of Chemistry, Massachusetts Institute of Technology, Cambridge, Massachusetts \\ 02139
}

\section{Abstract}

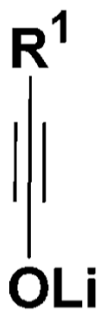

1
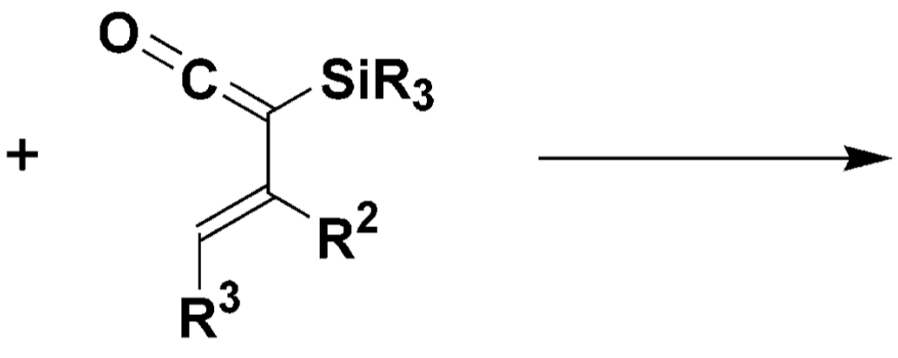

2<smiles>[R]c1cc(O[AsH])c([R])c(O)c1[R]</smiles>

3

(Trialkylsilyl)vinylketenes react with lithium ynolates to produce highly substituted phenols in a new benzannulation strategy that proceeds via the $6 \pi$ electrocyclization of an intermediate 3-(oxido) dienylketene.

\begin{abstract}
Vinylketenes ${ }^{1}$ function as versatile four-carbon building blocks in a variety of useful methods for the synthesis of carbocyclic and heterocyclic compounds. For example, research in our laboratory has shown that $[2+2]$ cyclo-additions of vinylketenes can serve as triggering steps in several "pericyclic cascade" strategies for the synthesis of six- and eight-membered carbocyclic compounds. ${ }^{2}$ Like most ketenes, however, vinylketenes are rarely isolable species and generally must be generated as transient intermediates for in situ trapping with ketenophilic $\pi$ bonds. In previous studies, we have demonstrated that (trialkylsilyl)vinylketenes ("TASvinylketenes") are remarkably stable ketenes and exhibit reactivity complementary to other vinylketenes in many useful synthetic reactions. In these transformations, the silyl substituent3 suppresses the tendency of vinylketenes to undergo dimerization and [2+2] cycloaddition, allowing them to express their underlying reactivity as electron-rich dienes in Diels-Alder cycloadditions 4 and as reactive carbonyl compounds in $[4+1]$ annulation reactions.5, 6 In this Letter we now report a new transformation of these versatile synthons: the reaction of TAS-vinylketenes with lithium ynolates in a new benzannulation strategy for the synthesis of substituted phenols (eq 1).
\end{abstract}

(C) 2005 American Chemical Society

danheisr@mit.edu.

Supporting Information Available: Experimental procedures and characterization data for 4c,d, 5c,d, 6c,d, 9c,f,g, and 15-24. This material is available free of charge via the Internet at http://pubs.acs.org. 


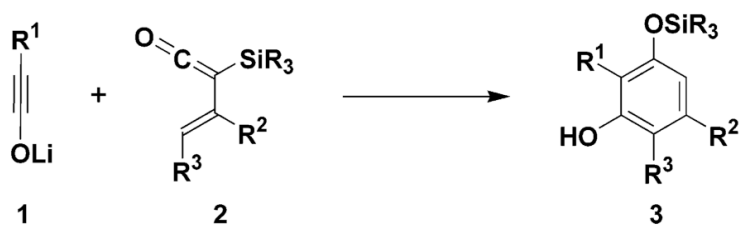

The TAS-vinylketenes 6a-6d required for this investigation were prepared via the photochemical Wolff rearrangement of $\alpha^{\prime}$-silyl- $\alpha^{\prime}$-diazo- $\alpha, \beta$-unsaturated ketones ${ }^{4 b}$ (Scheme 1). The requisite photo-Wolff substrates $(\mathbf{5 a}-\mathbf{5 d})$ were synthesized by silylation ${ }^{7}$ of the corresponding diazo ketones (4a-4d), which were obtained employing our detrifluoroacetylative diazo transfer procedure. ${ }^{8}$ As noted previously, TAS-vinylketenes are remarkably robust ketenes, stable at $25^{\circ} \mathrm{C}$ and at mildly elevated temperatures, and amenable to purification using conventional silica gel chromatography.

As shown in eq 1, lithium ynolates (1) serve as the second reaction partner in the proposed benzannulation. Recent studies have demonstrated that "ynolate anions" function as valuable synthetic intermediates in a number of useful transformations, and several reliable methods are now available for their preparation. ${ }^{9}$ For our initial studies, we focused our attention on the generation of lithium ynolates via the cleavage of siloxy alkynes ("silyl ynol ethers") with methyllithium. This method, first described by Kowalski, ${ }^{10}$ is a variant of the well-known strategy for the regiospecific generation of enolates introduced by Stork and Hudrlik.11 For our purposes, this process offered the attraction that it takes place under mild conditions and produces only inert tetraalkylsilanes as byproducts. In addition, the siloxy alkynes that serve as ynolate precursors can be conveniently prepared in one step from readily available acetylenes or esters. As shown in Scheme 2, siloxy alkynes 9d-9g were thus prepared in 69$90 \%$ yield employing the method of Julia, ${ }^{12}$ and alkynes 9a-9c were obtained via the Kowalski homologation of esters 7a-7c. ${ }^{10,13}$ As noted previously, these TIPS ynol ethers can be purified by distillation or careful chromatography and are stable to extended storage in solution at $0^{\circ}$ C.

Scheme 3 outlines the mechanistic pathway envisaged for the proposed ynolate benzannulation as well as several of the possible side reactions that we anticipated might compete with the desired reaction. C-Acylation of the ynolate by the TAS-vinylketene was expected to produce intermediate 10, with addition to the ketene occurring anti to the bulky trialkylsilyl group to afford the indicated $(Z)$-enolate. Several modes of cyclization for this densely functionalized intermediate are then conceivable. The addition of ynolates to aldehydes and ketones leads to the formation of $\beta$-lactone enolates, ${ }^{9}$ and an analogous reaction in this case would give rise to products of type 12. An alternative mode of ring closure would generate the four-membered carbocycle 13, an enolate derivative of a substituted 1,3-cyclobutanedione. Our expectation, however, was that intermediate $\mathbf{1 0}$ would most likely undergo facile $6 \pi$ electrocyclic ring closure to afford the desired cyclohexadienone 11. ${ }^{14-16}$ Favoring this mode of cyclization is the $(Z)$-enolate geometry of $\mathbf{1 0}$, which enforces close proximity between the C-1 and C-6 carbon atoms at which bond formation is desired to occur. Also important is the significant increase in charge stabilization that should develop in the transition state leading to the 1,3-dicarbonyl enolate system in 11. It was our expectation that these factors would suffice to favor the desired mode of ring closure over alternative cyclization pathways and intermolecular condensation reactions. 
The feasibility of the benzannulation was initially investigated using TAS-vinylketene 6a and the ynolate derived from the siloxy hexyne 9e. Exposure of 9e to 1 equiv of methyllithium in $\mathrm{THF}$ at room temperature led to complete consumption of the siloxy alkyne within $3 \mathrm{~h}$ as monitored by TLC analysis. Upon addition of TAS-vinylketene $\mathbf{6 a}$, a new aromatic product rapidly appeared that was isolated in $62 \%$ yield after purification by silica gel chromatography. Interestingly, this benzannulation product was identified as the silyl ether $\mathbf{1 5}$ (Table 1) rather than the originally expected resorcinol of type $\mathbf{1 4}$. We speculate that the initially formed electrocyclization product $\mathbf{1 1}$ isomerizes under the conditions of the benzannulation to produce a 6-silyl-2,4-cyclohexadienone intermediate that aromatizes via a 1,3 carbon $\rightarrow$ oxygen silyl shift. 1,3-Silyl shifts in $\alpha$-silyl ketones to form silyl enol ethers are well-known processes, ${ }^{17}$ and related rearrangements involving silylcyclohexadienones have been observed in our laboratory ${ }^{4 \mathrm{~b}}$ and others. ${ }^{18}$

Previous studies in our laboratory have demonstrated that TAS-vinylketenes behave as electron-rich dienes in Diels-Alder reactions and react best with electron-deficient dienophiles. $4 \mathrm{~b}, \mathrm{c}$ In view of these prior observations, we were not surprised to find that no reaction occurs upon heating TAS-vinylketene $\mathbf{6 a}$ and siloxy alkyne $\mathbf{9 e}$ in refluxing toluene, and attempted reaction in the presence of Lewis and Bronsted acids (e.g., $\mathrm{ZnI}_{2}, \mathrm{TiCl}_{4}, \mathrm{AgNTf}_{2}, \mathrm{HNTf}_{2}$ ) resulted only in complex mixtures of products.

Table 1 delineates the scope of the ynolate benzannulation reaction. Optimization studies revealed methyllithium to be the most effective agent for the generation of ynolates from siloxy alkynes $9 \mathbf{a}-9 \mathrm{~g}$, and low yields of the desired benzannulation products were obtained when TBAF, TBAT, or $\mathrm{KOEt}^{19}$ were substituted for MeLi in the reaction. A variety of siloxy alkynes and vinylketenes participate in the benzannulation, and branching is accommodated on either annulation component. Unfortunately, attempts thus far to extend the reaction to include TASarylketenes have not been successful. In addition, low yields of the desired product were obtained upon attempted benzannulation with the allyl-substituted acetylene $9 \mathbf{f}$, apparently as a result of competitive metalation at the methylene carbon by MeLi during the ynolate generation step. ${ }^{20}$ This problem was easily circumvented, however, by substituting the TBDMS ynol ether $\mathbf{2 3}^{21}$ for the TIPS derivative 9 f as the ynolate precursor (entry 8). Cleavage of this siloxy alkyne with MeLi is complete within minutes, and upon reaction with TASvinylketene $\mathbf{6 b}$ the desired benzannulation product $\mathbf{2 2}$ is obtained in good yield.

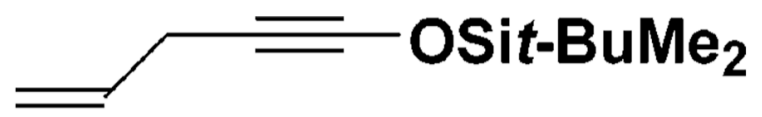

\section{3}

In summary, TAS-vinylketenes react with lithium ynolates in a regiocontrolled benzannulation process that provides efficient access to highly substituted aromatic compounds. We anticipate that these annulation products should serve as useful intermediates in a variety of further synthetic transformations. Phenols such as $\mathbf{2 1}$ and $\mathbf{2 2}$ are of particular interest, as the unsaturated ortho substitutents can provide the basis for subsequent cyclization reactions to form a variety of oxygen heterocycles including benzofurans and benzopyrans. ${ }^{22}$ For example, as illustrated in Scheme 4, treatment of $\mathbf{2 2}$ with catalytic $\mathrm{PdCl}_{2}(\mathrm{MeCN})_{2}$ in the presence of benzoquinone and $\mathrm{LiCl}^{23}$ furnished the tetrahydronaphthofuran $\mathbf{2 4}$ in good yield.

\section{Supplementary Material}

Refer to Web version on PubMed Central for supplementary material. 


\section{Acknowledgments}

We thank the National Institutes of Health (GM 28273) and Merck Research Laboratories for generous financial support. Y.Z. was supported by a Po Ting Ip Fellowship.

\section{References}

1. Reviewed in: Tidwell, TT. Ketenes. New York: Wiley; 1995.

2. (a) Danheiser RL, Martinez-Davila C, Sard H. Tetrahedron 1981;37:3943. (b) Danheiser RL, Gee SK, Sard H. J. Am. Chem. Soc 1982;104:7670. (c) Danheiser RL, Gee SK. J. Org. Chem 1984;49:1672. (d) Danheiser RL, Brisbois RG, Kowalczyk JJ, Miller RF. J. Am. Chem. Soc 1990;112:3093.

3. For reviews of the chemistry of silylketenes, see ref 1 and (a) Pommier A, Kocienski P, Pons J-M. J. Chem. Soc., Perkin Trans 1998;1:2105. (b) Schaumann, E.; Scheiblich, S. Methoden der Organischen Chemie (Houben Weyl). Kropf, E.; Schaumann, E., editors. Vol. Vol. E15. Stuttgart, Germany: Thieme; 1993. (c) Pons, J-M.; Kocienski, PJ. Science of Synthesis: Houben Weyl Methods of Molecular Transformations. Fleming, I., editor. Vol. Vol. 4. Stuttgart, Germany: Thieme;

4. (a) Danheiser RL, Sard H. J. Org. Chem 1980;45:4810. (b) Loebach JL, Bennett DM, Danheiser RL. J. Org. Chem 1998;63:8380. (c) Bennett DM, Okamoto I, Danheiser RL. Org. Lett 1999;1:641. [PubMed: 10823193]

5. (a) Loebach JL, Bennett DM, Danheiser RL. J. Am. Chem. Soc 1998;120:9690. (b) Dalton AM, Zhang Y, Davie CP, Danheiser RL. Org. Lett 2002;4:2465. [PubMed: 12123352] (c) Rigby JH, Wang Z. Org. Lett 2003;5:263. [PubMed: 12556167] (d) Davie CP, Danheiser RL. Angew. Chem., Int. Ed. In press.

6. For related reactions involving silylated bisketenes, see: (a) Colomvakos JD, Egle I, Ma J, Pole DL, Tidwell TT, Warkentin J. J. Org. Chem 1996;61:9522. (b) Huang W, Tidwell TT. Synthesis 2000:457. (c) Allen AD, Huang W-W, Moore PA, Far AR, Tidwell TT. J. Org. Chem 2000;65:5676. [PubMed: 10970310]

7. (a) Maas G, Brückmann R. J. Org. Chem 1985;50:2801. (b) Brückmann R, Schneider K, Maas G. Tetrahedron 1989;45:5517.

8. (a) Danheiser RL, Miller RF, Brisbois RG, Park SZ. J. Org. Chem 1990;55:1959.(b) Danheiser, RL.; Miller, RF.; Brisbois, RG. Organic Syntheses. Vol. Vol. IX. New York: Wiley; 1998. p. 197Collect

9. For reviews of the chemistry of ynolates, see: (a) Shindo M. Synthesis 2003:2275. (b) Shindo M. Chem. Soc. Rev 1998;27:367.

10. Kowalski CJ, Lal GS, Haque MS. J. Am. Chem. Soc 1986;108:7127.

11. Stork G, Hudrlik PF. J. Am. Chem. Soc 1968;90:4464.

12. Julia M, Saint-Jalmes VP, Verpeaux J-N. Synlett 1993;233

13. Siloxy alkyne 9c (see Supporting Information) was prepared using a two-step variant of the Kowalski reaction; see: (a) Kowalski CJ, Fields KW. J. Am. Chem. Soc 1982;104:321. (b) Smith AB III, Adams CM, Kozmin SA, Paone DV. J. Am. Chem. Soc 2001;123:5925. [PubMed: 11414825]

14. The possibility that intermediate $\mathbf{1 1}$ might form via a concerted [4+2] cycloaddition of $\mathbf{1}$ and TASvinylketene 2 cannot be excluded.

15. For a discussion of the $6 \pi$ electrocyclization of 3-oxido-1,3,5-hexatrienes, see: Magnus P. NouV. J. Chem 1978;2:555.

16. For prior examples of $6 \pi$ electrocyclization reactions involving enolate derivatives, see: (a) White JD, Skeean RW. J. Am. Chem. Soc 1978;100:6296. (b) White JD, Skeean RW, Trammell GL. J. Org. Chem 1985;50:1939. (c) Magomedov NA, Ruggiero PL, Tang Y. J. Am. Chem. Soc 2004;126:1624. [PubMed: 14871080] (d) Magomedov NA, Ruggiero PL, Tang Y. Org. Lett 2004;6:3373. [PubMed: 15355055] and references therein.

17. For a recent theoretical study and leading references, see: Takahashi M, Kira M. J. Am. Chem. Soc 1999;121:8597.

18. (a) Moser WH, Sun L, Huffman JC. Org. Lett 2001;3:3389. [PubMed: 11594841] (b) Chamberlin S, Wulff WD. J. Org. Chem 1994;59:3047. (c) Fogel L, Hsung RP, Wulff WD, Sommer RD, Rheingold AL. J. Am. Chem. Soc 2001;123:5580. [PubMed: 11389643]

19. Yu W, Jin Z. Tetrahedron Lett 2001;42:369. 
20. The metalation of 1-phenyl-4-penten-1-yne with MeLi has previously been reported: Klein J, Brenner S, Medlik A. Isr. J. Chem 1971;9:177.

21. The TBDMS siloxy alkyne $\mathbf{2 3}$ was prepared from allylacetylene by employing the method of Julia (see Supporting Information). In general, however, the use of TIPS derivatives is preferred because of their increased stability to purification and storage.

22. Reviewed in: Zeni G, Larock RC. Chem. Rev 2004;104:2285. [PubMed: 15137792]

23. These conditions have been employed by Hegedus for the cyclization of 2-allylanilines to indoles. See: Hegedus LS, Allen GF, Bozell JJ, Waterman EL. J. Am. Chem. Soc 1978;100:5800. 
i- $\mathrm{Pr}_{3} \mathrm{SiOTf}, i-\mathrm{Pr}_{2} \mathrm{EtN}$<smiles>[R]C=C([R2])C(=O)C=[W]</smiles>

4a-d

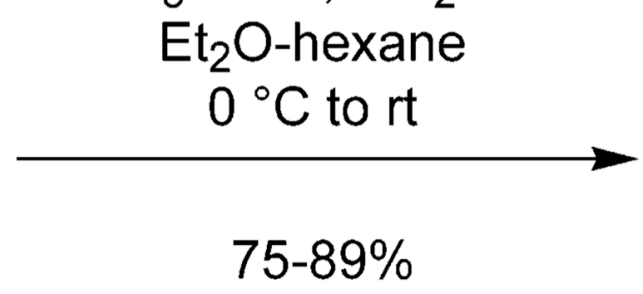

$\mathbf{a}^{a} \mathrm{R}^{2}=\mathrm{CH}_{3}, \mathrm{R}^{3}=\mathrm{CH}_{3}$

b $^{a} \mathrm{R}^{2}, \mathrm{R}^{3}=-\left(\mathrm{CH}_{2}\right)_{4}^{-}$

c $\mathrm{R}^{2}=\mathrm{CH}_{3}, \mathrm{R}^{3}=\mathrm{Et}$

d $\mathrm{R}^{2}=\mathrm{CH}_{3}, \mathrm{R}^{3}=\mathrm{C}_{6} \mathrm{H}_{11}$

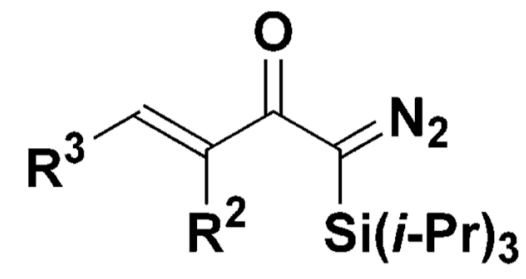

$5 a-d$

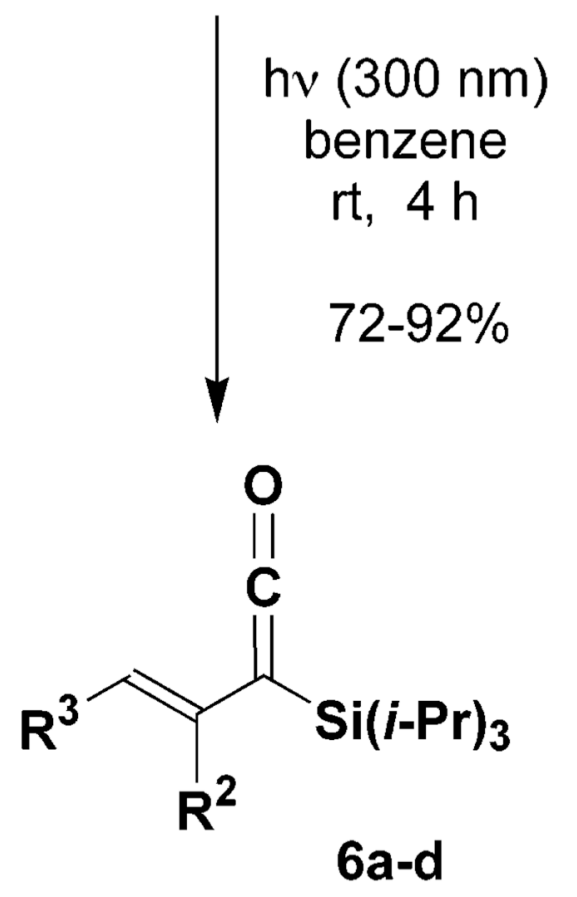

Scheme 1.

${ }^{a}$ For the prior preparation of $\mathbf{4 a}, \mathbf{b}, \mathbf{5 a}, \mathbf{b}$, and $\mathbf{6 a}, \mathbf{b}$, see ref $4 \mathrm{~b}$. 


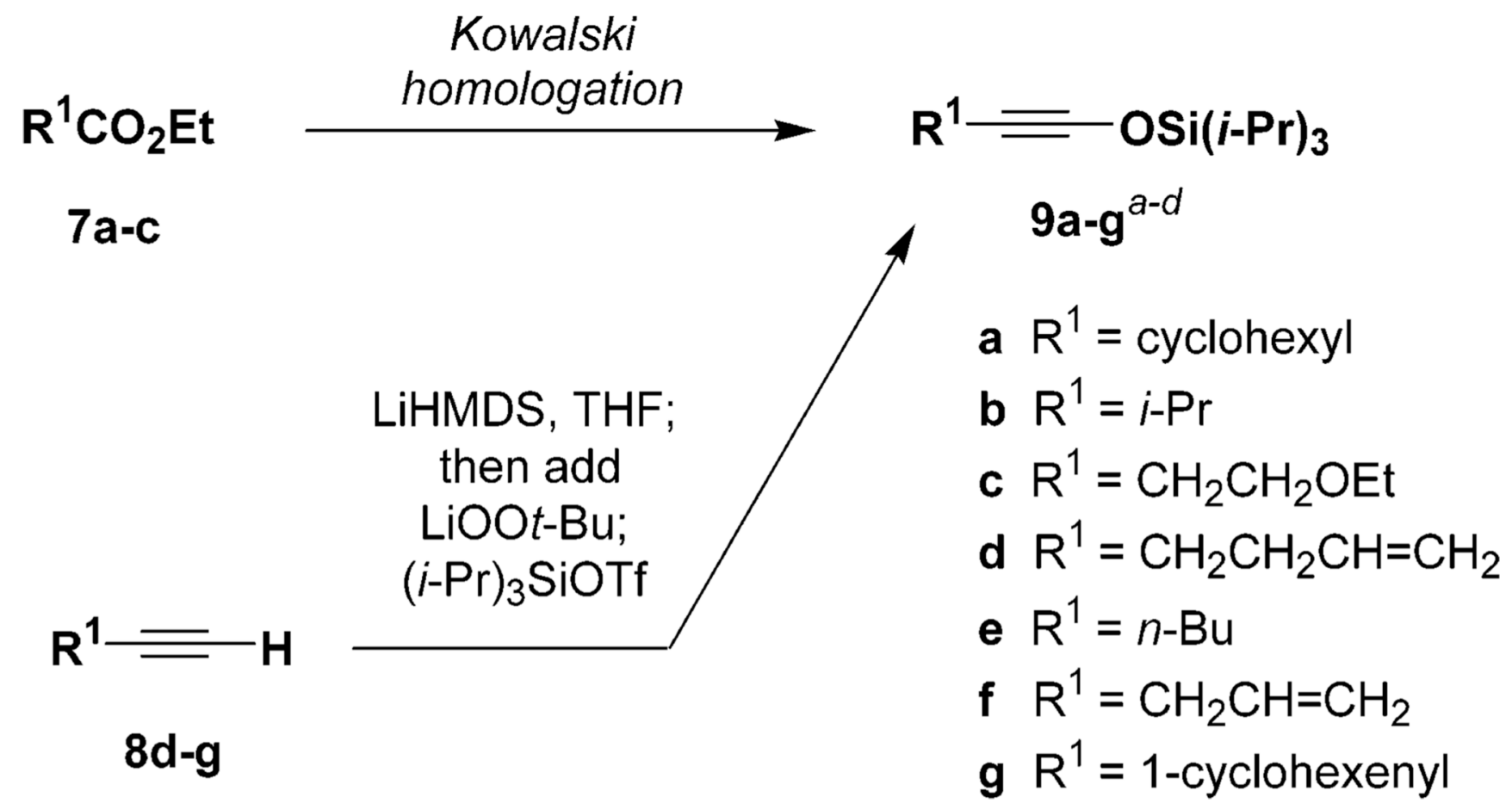

Scheme 2.

a 9a: ref ${ }^{10} .{ }^{b}$ 9b: Danheiser, R. L.; Helgason, A. L. J. Am. Chem. Soc. 1994, 116, 9471. ${ }^{c}$ 9d:

Zang, L.; Kozmin, S. A. J. Am. Chem. Soc. 2004, 126, 10204. ${ }^{d}$ 9e: Sweis, R. F.; Schramm,

M. P.; Kozmin, S. A. J. Am. Chem. Soc. 2004, 126, 7442. 


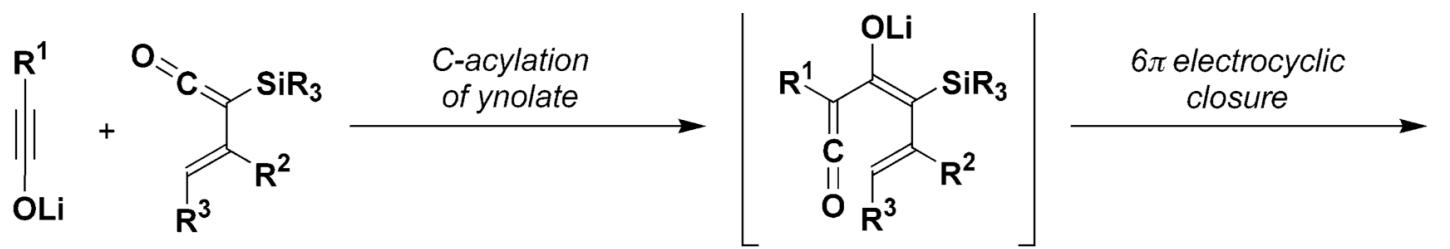<smiles>[R]C1=C(Cl)C([R3])=C([R])C([R])C1=O</smiles>

10
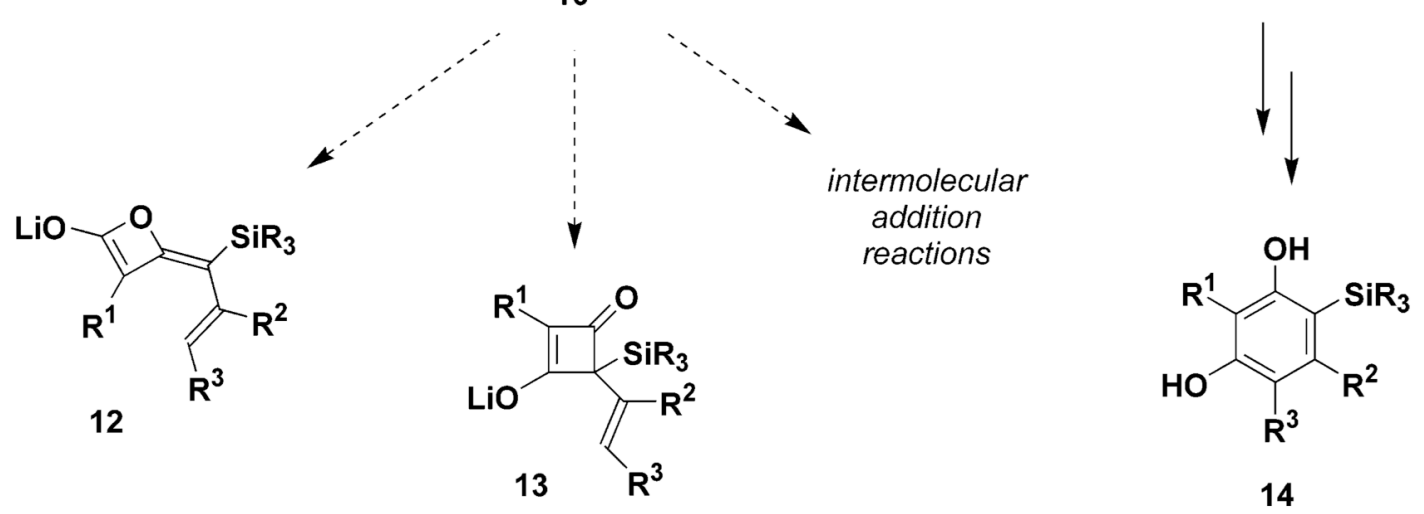

Scheme 3.

Org Lett. Author manuscript; available in PMC 2010 July 6. 

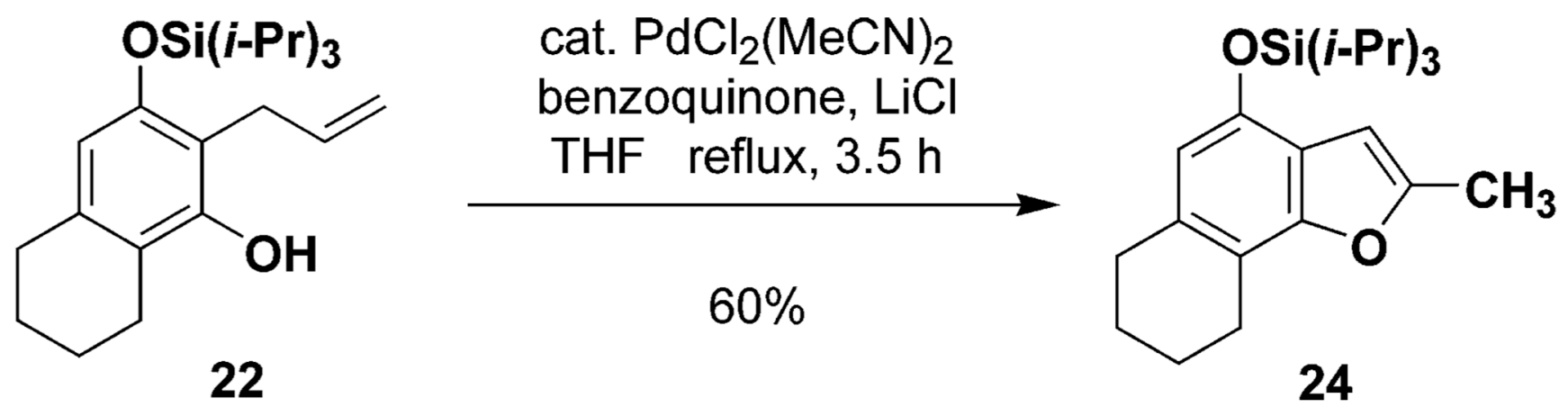

Scheme 4. 


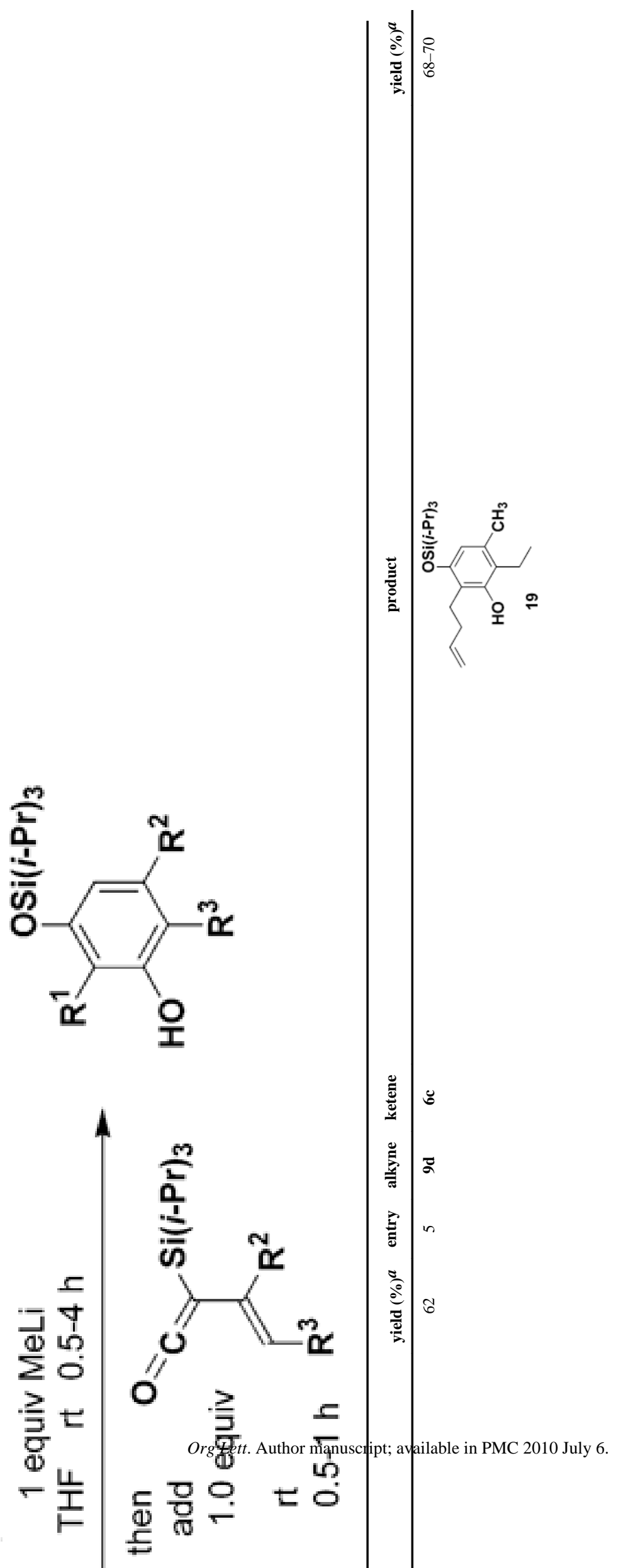




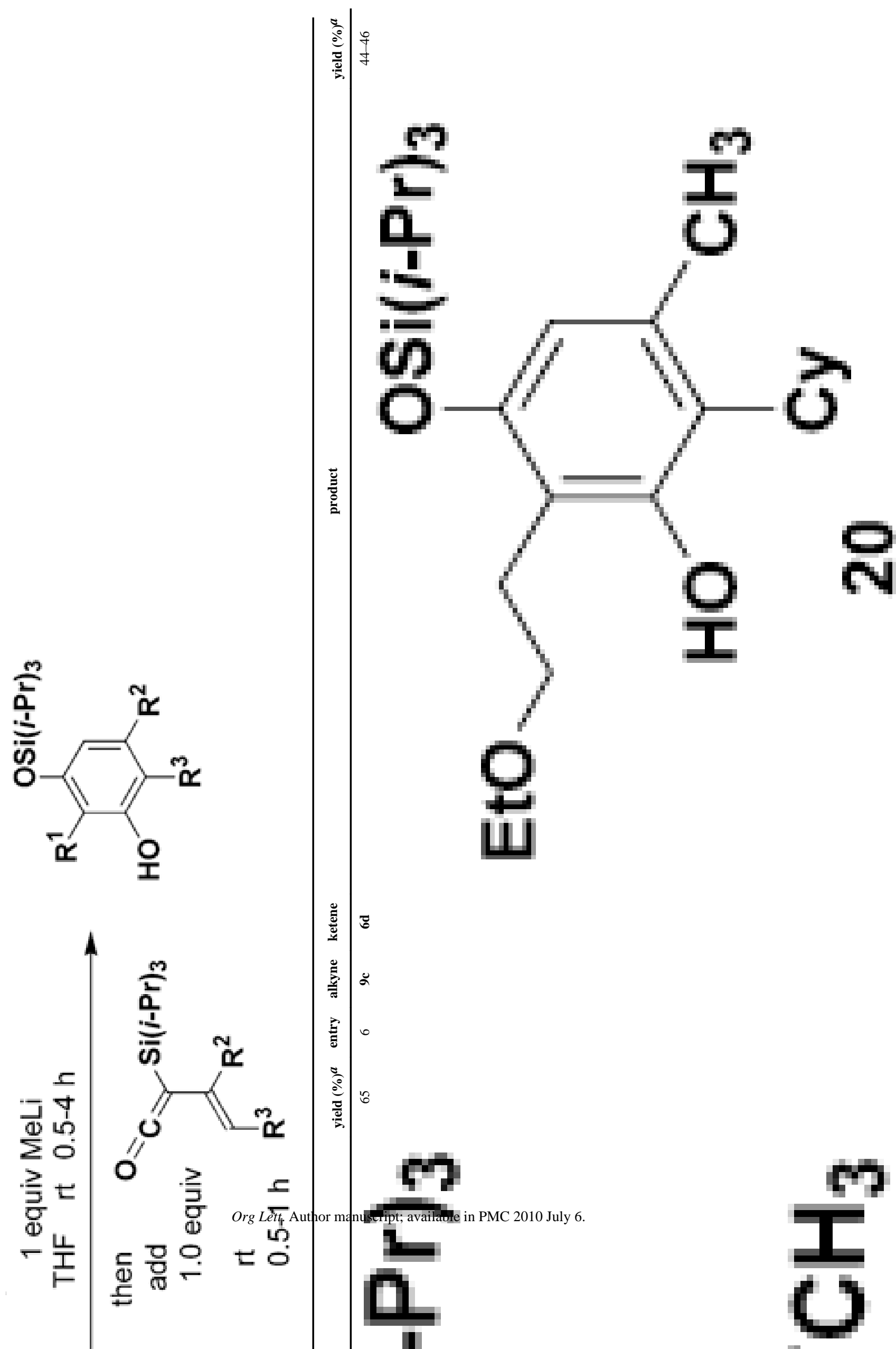




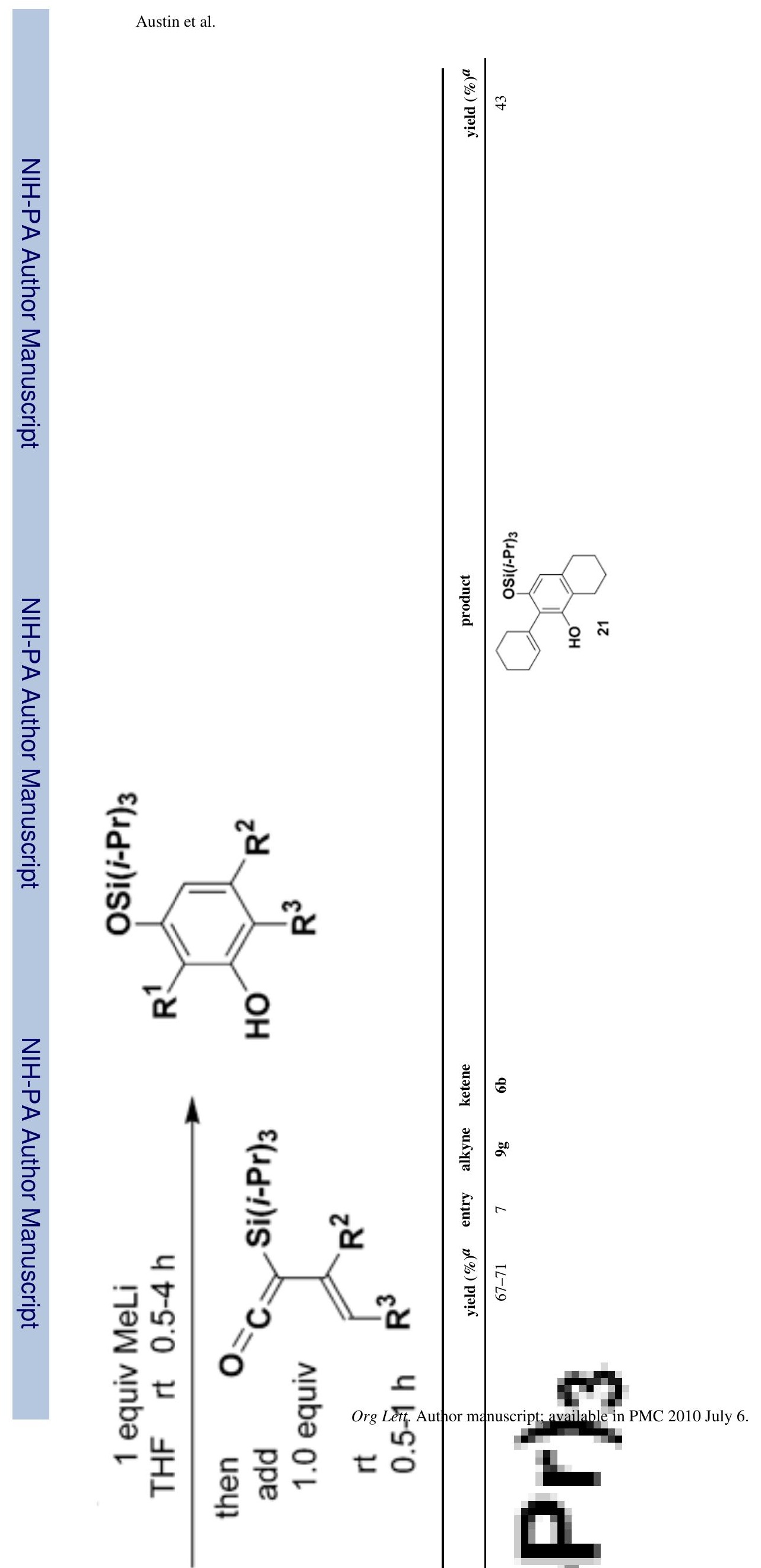




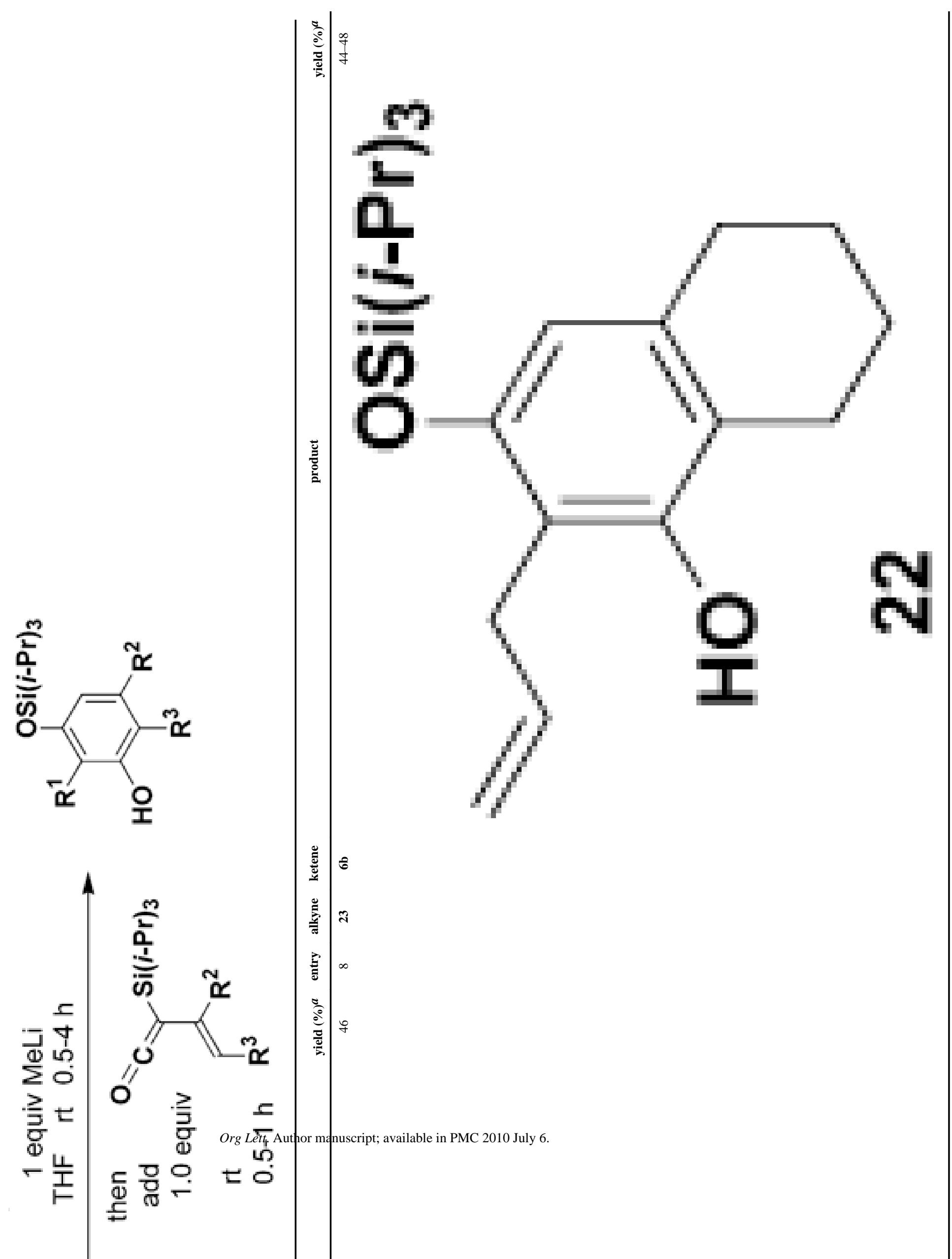


